\title{
Modified Canal Wall Down Mastoidectomy Without Meatoplasty
}

\author{
You Young An $\mathbb{D}$ and Jong Dae Lee ${ }^{\mathbb{D}}$ \\ Department of Otorhinolaryngology-Head and Neck Surgery, Bucheon Hospital, Soonchunhyang University College of Medicine, \\ Bucheon, Korea
}

\section{외이도성형술을 시행하지 않는 변형 개방동 유양돌기절제술}

안유영 · 이종대

순천향대학교 의과대학 부천병원 이비인후-두경부외과학교실

\author{
Received August 20,2021 \\ Revised October 5, 2021 \\ Accepted October 18, 2021 \\ Address for correspondence \\ Jong Dae Lee, MD, PhD \\ Department of Otorhinolaryngology- \\ Head and Neck Surgery, \\ Bucheon Hospital, \\ Soonchunhyang University \\ College of Medicine, \\ 170 Jomaru-ro, \\ Bucheon 14584, Korea \\ Tel $+82-32-621-5015$ \\ Fax $+82-32-621-5016$ \\ E-mail1jdent@schmc.ac.kr
}

It is important to decide which procedure to employ between canal wall up mastoidectomy and canal wall down mastoidectomy (CWDM) as each procedure has its own advantages and disadvantages. To combine the advantages and compensate the disadvantages of each procedure, various methods and approaches have been devised. Mastoid and epitympanic obliteration, which minimizes the dead space in the mastoid cavity, was previously known to prevent the occurrence of retraction pockets. We performed mastoid and epitympanic obliteration also to prevent the occurrence of cavity problems without meatoplasty. Here we describe the surgical procedures for modified CWDM without meatoplasty and mastoid obliteration using autologous materials. Korean J Otorhinolaryngol-Head Neck Surg 2021;64(12):965-70

\section{서 론}

유양돌기절제술(mastoidectomy)의 목적은 병소를 완전히 제거하고 중이의 해부학적 구조를 재건하는 것이다. 유양돌기 절제술의 술식은 크게 두 가지로, 외이도 후벽을 보존하는 폐 쇄동 유양돌기절제술(canal wall up mastoidectomy)과, 외 이도 후벽을 절제하여 상고실과 유양동을 하나의 공동으로 만드는 개방동 유양돌기절제술(canal wall down mastoidectomy, CWDM)이 있다. 술식을 선택하는 데 있어 병변이나 청력, 유양돌기 함기화 정도, 이관기능 등의 요인들에 대해 고 려해야 한다. 폐쇄동 유양돌기절제술은 외이도와 고막의 생 리학적 구조와 기능을 유지할 수 있고, 술후 공동문제가 적

This is an Open Access article distributed under the terms of the Creative Common Attribution Non-Commercial License (https://creativecommons.org/licenses/by-nc/4.0) which permits unrestricted non-commercial use, distribution, and reproduction in any medium, provided the original work is properly cited.
거나 보청기 착용이 용이하다는 장점이 있지만, 후고실개방 술(posterior tympanotomy)을 필수적으로 시행하더라도 개 방동 유양돌기절제술에 비해 수술 시야가 제한적이기 때문에 잔존 혹은 재발 진주종의 비율이 상대적으로 높고, 추적 관 찰 시 진주종의 재발 유무를 확인하기 위해서 이차수술이 필 요 경우가 많다. ${ }^{1-3)}$ 또한 이관기능부전이 악화되면, 술후 고막 함몰이 발생하거나, 진주종이 재발할 수 있어 지속적인 추적 관찰이 필요하다. 진주종의 범위가 광범위하거나 이관기능이 불량한 경우, 고실-유양돌기가 심한 경화상(sclerotic)인 경우 에서는 개방동 유양돌기절제술의 적응증이 될 수 있다. 전통 적인 개방동 유양돌기절제술(traditional CWDM) 술식에서 는 외이도성형술(meatoplasty)을 함께 시행하는데, 술후 넓어 진 공동을 잘 관찰할 수 있도록 하기 때문에 잔존 혹은 재발 진주종의 비율이 낮고, 추적 관찰 시에도 재발 여부의 조기 발견이 가능할 수 있다는 장점이 있지만, 외이도의 생리학적 
구조를 유지할 수 없고, 넓어진 외이도로 인해 추후 보청기 착용 시에 문제가 발생하거나 온도나 압력 변화에 어지럼이 유발될 수 있다.,5) 안면신경능을 충분히 낮추지 않거나, 외이 도 성형술을 시행하지 않은 개방동 유양돌기절제술에서는 중이와 유양동의 해부학적 구조 및 생리의 변화로 인해 각질 파편(keratin debris)이 축적되고 이로 인해 젖은 귀(draining ear)같은 공동문제를 일으킬 수 있다.,6)

개방동 유양돌기절제술의 문제점들을 극복하기 위해, 외이 도 후벽을 재건하거나(canal wall reconstruction), 유양돌기 를 폐쇄하는 등 다양한 변형된 술식들을 개발하였다. 유양돌 기폐쇄술(mastoid obliteration)은 개방동 유앙돌기 절제술 후 지나치게 큰 유양동의 크기를 줄여주는 술식으로 주로 사용 되는 방법으로, 기저 피판(pedicled flap), ${ }^{78}$ 지방,9) 연골, ${ }^{10,11)}$ 골분(bone pate), ${ }^{9,12)}$ 동종골(bone chip), ${ }^{8)}$ 그리고 수산화인회 석(hydroxyapatite $)^{10,13)}$ 과 같은 다양한 재료가 사용된다.

저자는 외이도성형술로 인한 단점을 피하고 공동문제를 예 방할 수 있는 변형 개방동 유양돌기절제술을 고안하여, 이 술 식에 대한 효율성과 안전성을 보고한 바 있다. ${ }^{14)}$ 외이도 성형 술을 시행하지 않고 자가조직을 이용하여 유양돌기폐쇄술을 시행하는 변형 개방동 유양돌기절제술의 준비와 수술 과정 을 저자의 경험과 함께 소개하고자 한다.

\section{방 법}

\section{수술 전 평가(preoperative assessment)}

수술 전 영상의학적 평가과정 및 적응증은 전통적인 개방 동 유양돌기절제술을 요하는 일반적인 경우와 다르지 않다. 다만, 외이도 성형술을 시행하지 않고 유양돌기폐쇄술만으로 도 각질 이동 및 환기가 잘 되어 공동문제가 발생하지 않도록 측두골 전산화단층촬영을 통해 유양동이 크지 않거나, 경화 성 유양동(sclerotic mastoid)임을 확인해야한다.

\section{수술 술기(operative procedure)}

\section{환자 위치 잡기}

후이개 접근법을 위해 수술하는 귀의 뒤와 윗부분 머리카 락을 약 $3 \mathrm{~cm}$ 정도 면도 후 환자의 고개를 반대측으로 돌려 수술하는 쪽의 귀가 노출될 수 있게 한다. 수술 전 외이도를 청결하게 하고, 고막 천공이 동반될 시 소독제가 중이 내로 들어가지 않도록 주의한다.

\section{절개선 고안 및 피판 거상}

이개후 주름(postauricular crease)에서 약 5-10 mm 정도 뒷부분에 유양돌기 첨부(mastoid tip)에서 이개 연골의 부착 부위 위까지 절개선을 도안한다. 1:100000 epinephrine을 이 용하여 절개선을 따라 후이개부 피하 마취를 하고, 외이도의 상방과 하방의 고실인부봉합선(tympanosquamous suture line)과 고실유돌봉합선(tympanomastoid suture line)에 외 이도 피부가 하얗게 변하는 것을 확인하면서 1:100000 epinephrine을 천천히 주사한다. 이때 외이도 내에 수포가 생기 지 않도록 바늘의 베벨을 골막 쪽으로 항하여 천천히 주입하 는 것이 중요하다. 이후 후이개 절개선을 따라 피부 절개를 시행하고, 전기소작기를 이용하여 바닥에 연부조직층을 보존 하면서 피하조직을 박리한다.

\section{측두근막 채취 및 확대 하방기저 근골막 피판(extended} inferior based musculoperiosteal flap, extended IBF) 거상

피부 피판 거상 후 측두근이 노출되면 측두근막(temporalis muscle fascia)을 가능한 크게 얻은 후 말린다. 추후 상고 실과 유양동 폐색에 사용할 extended IBF를 디자인하고 들 어올린다(Fig. $1 \mathrm{~A}$ and B). 측두근을 포함하여 최대한 길게 피판을 들어올리는 것이 좋고, 이때 이 피판에 혈액을 공급 하는 이개후동맥의 손상을 피하도록 한다.
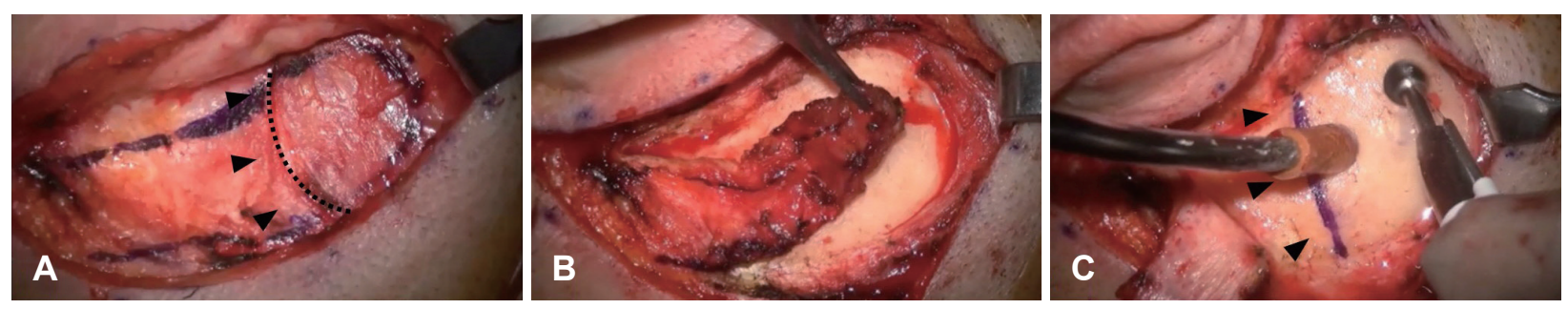

Fig. 1. Design the extended inferior based flap and collect the bone pate in the left ear. Design the extended inferior based flap over temporal line (arrowheads) ( $\mathrm{A}$ and $\mathrm{B}$ ). Collect the healthy cortical bone pate from only the temporal area above the temporal line (arrowheads) (C). 
피질골 골편(bone pate) 채취

유양동 견인기(mastoid retractor)를 이용하여 골막판을 젖 혀두고, 유양동 상부의 측두 부위에서 감염된 함기세포가 없 는 건강한 피질골을 절단형 버어(cutting burr)를 이용하여 채취한 후 유리병에 모은다(Fig. 1C). 모은 골편은 포비돈-요 오드 용액(povidone-iodine solution)을 이용하여 소독하고, 생리식염수로 충분히 세척 후 건조시킨다.

유양돌기절제술(mastoidectomy via inside-out approach) 시행

최대한 외이도 후벽의 피부 피판을 보존하면서 고실외이도 피판(tympanomeatal flap)을 만들어 골부 외이도에서 내측 으로 분리 후 고실 견인기(temporal retractor)로 손상되지 않 도록 보존한다. 유양돌기절제술을 시작하는데, 골부 외이도 후상방으로부터 유양동과 상고실 방향으로 진행하는 내외방 식(inside-out approach)으로 절단형 버어를 사용하여 진주 종, 함기낭, 미란된 이소골을 포함한 모든 병변 부위를 제거 한다(Fig. 2). 모든 병변부위는 제거하되 불필요한 드릴링으 로 유양동의 크기를 넓히지는 않도록 한다. 부위는 침등관절 (incudostapedial joint)을 조심스럽게 분리한 후 침골(incus) 과 등골 두부(malleus head)를 제거하여야 하고, $\operatorname{cog}$ 를 제거 하여 상고실 전부(anterior epitympanum)를 확인하고, 뒤쪽 으로는 안면신경능(facial ridge)을 충분히 낮추어 주는 것이 중요하다. S자 정맥동이나 안면신경 위의 얇은 뼈를 삭개할 때는 다이아몬드 버어를 사용하는 것이 좋으며 안면신경에 대한 수술 중 신경감시기(intraoperative nerve monitor)를 사용하여 안면신경의 손상을 예방한다.

\section{상고실 폐색(attic obliteration)}

이갑개 연골(conchal cartilage)에서 연골을 채취 후 연골 압착기(cartilage crusher)을 이용하여 분쇄한 연골편을 안면 신경의 고실분절 상부인 유양동과 상고실에 채운다(Fig. 3). 연골을 지지하고 연골이 중이 내로 들어가는 것을 예방하기 위해 Fibrin sealant (Baxter AG, Vienna, Austria)를 이용 하여 고정해준다.

유양동 폐색(mastoid obliteration) 및 고막 재건

수술로 인해 함몰된(bowlike) 유양동을 편평하게 만들고
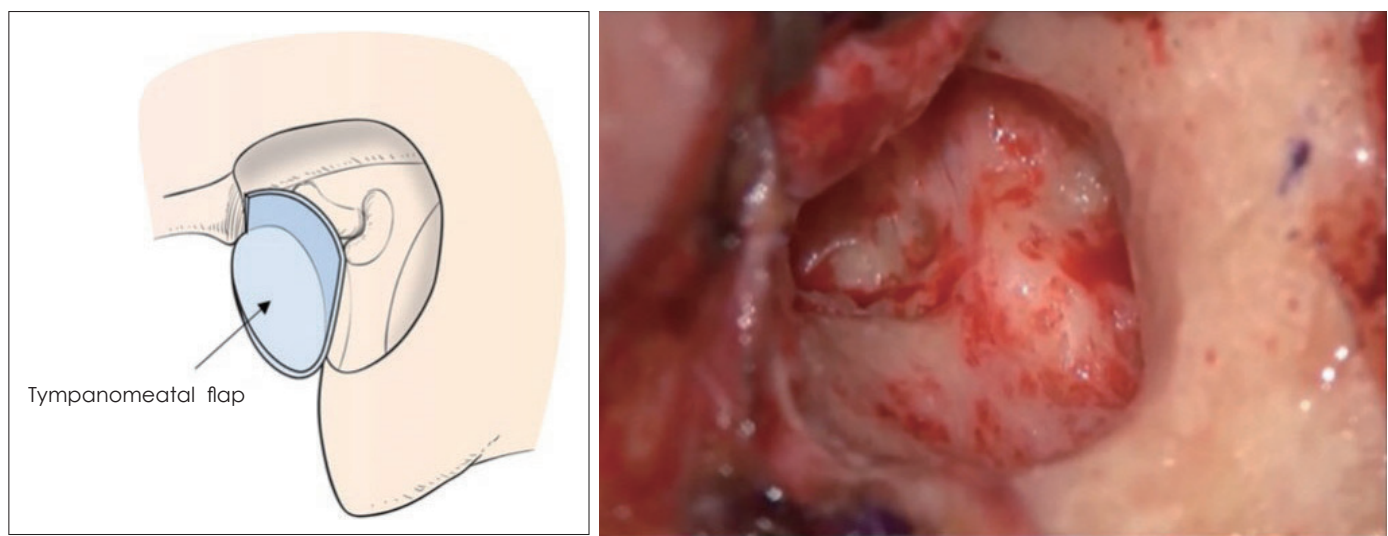

Fig. 2. Mastoidectomy via inside-out approach. Adapted from Kim, et al. Clin Exp Otorhinolaryngol 2019;12(4):360-6. ${ }^{14)}$
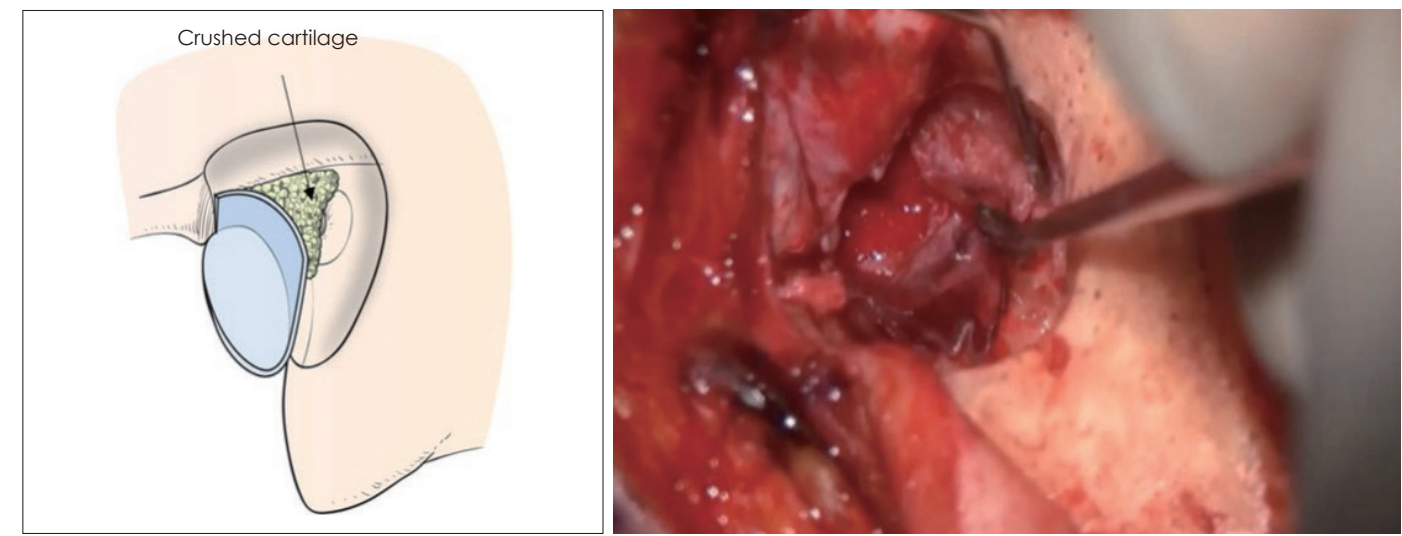

Fig. 3. Obliteration of mastoid antrum and epitympanic space with crushed conchal cartilage. Adapted from Kim, et al. Clin Exp Otorhinolaryngol 2019;12(4):360-6. ${ }^{14)}$ 


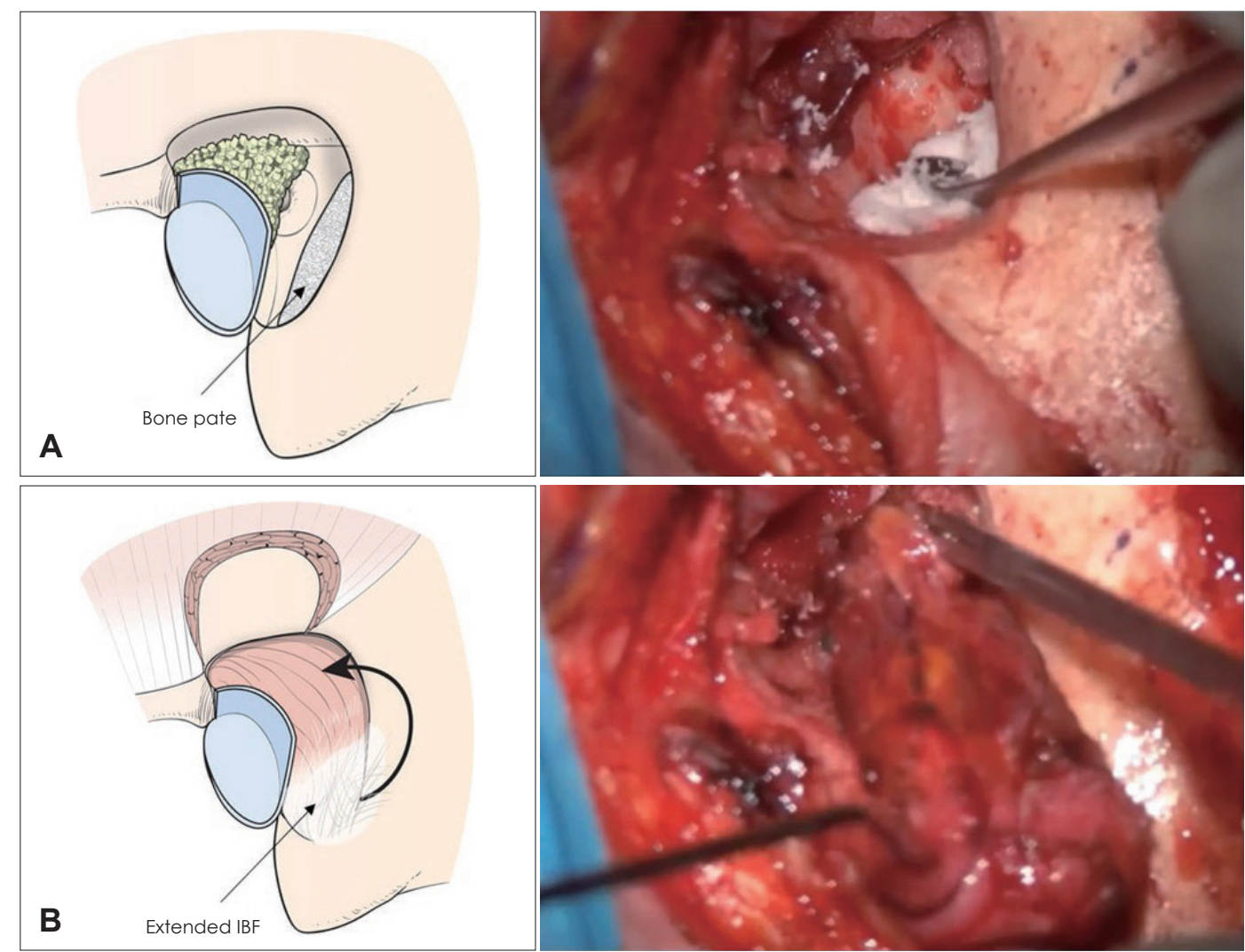

Fig. 4. Mastoid obliteration with bone pate (A) and extended inferior based flap (B). IBF, inferior based musculoperiosteal flap. Adapted from Kim, et al. Clin Exp Otorhinolaryngol 2019;12(4):360-6. ${ }^{14)}$

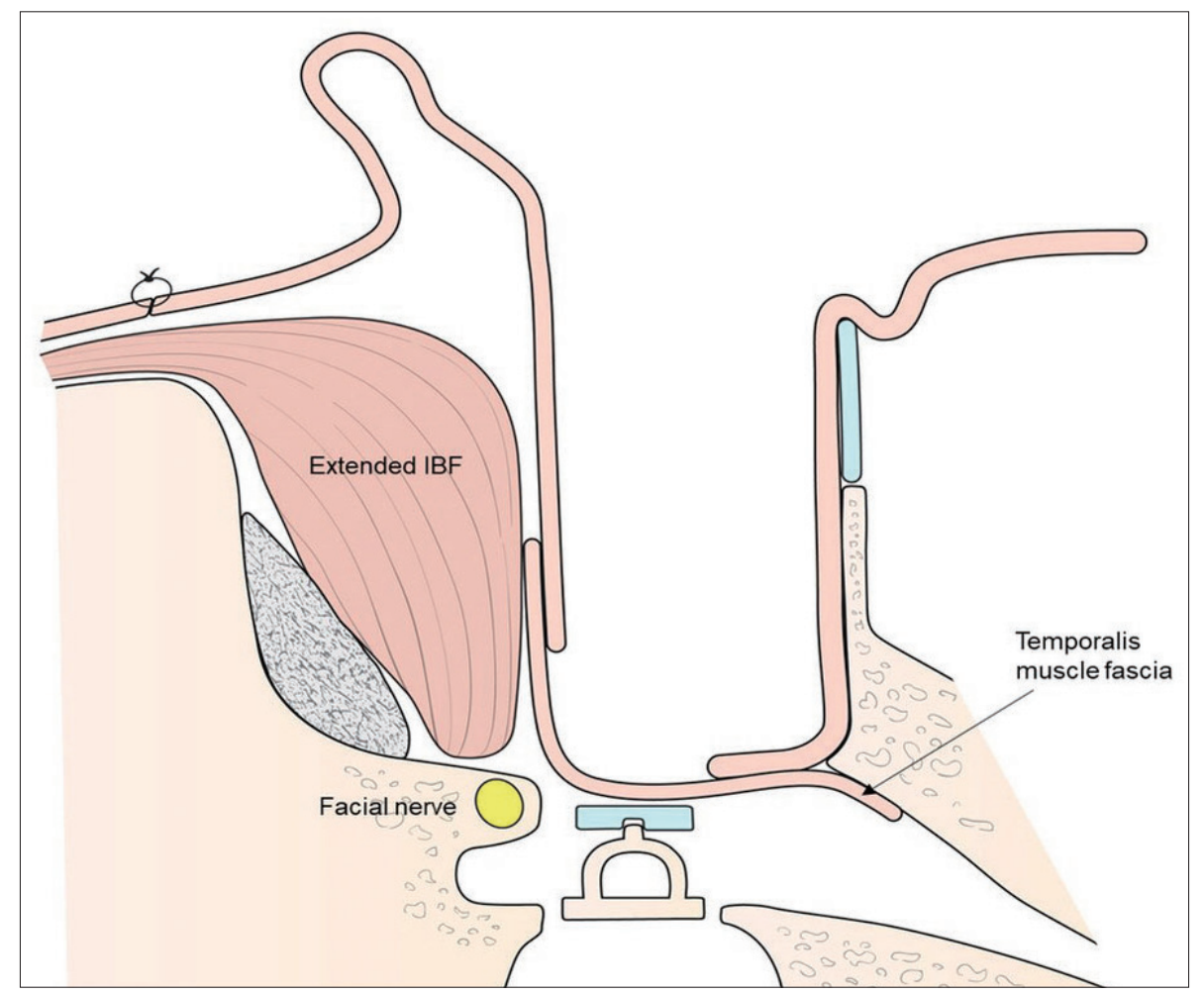

Fig. 5. Schematic drawing of the procedure: completion state of the modified canal wall down mastoidectomy and mastoid obliteration. A temporalis muscle facia graft is placed on the extended inferior based flap reconstructing of the tympanic membrane. IBF, inferior based musculoperiosteal flap. Adapted from Kim, et al. Clin Exp Otorhinolaryngol 2019;12(4):360-6. ${ }^{14)}$ 


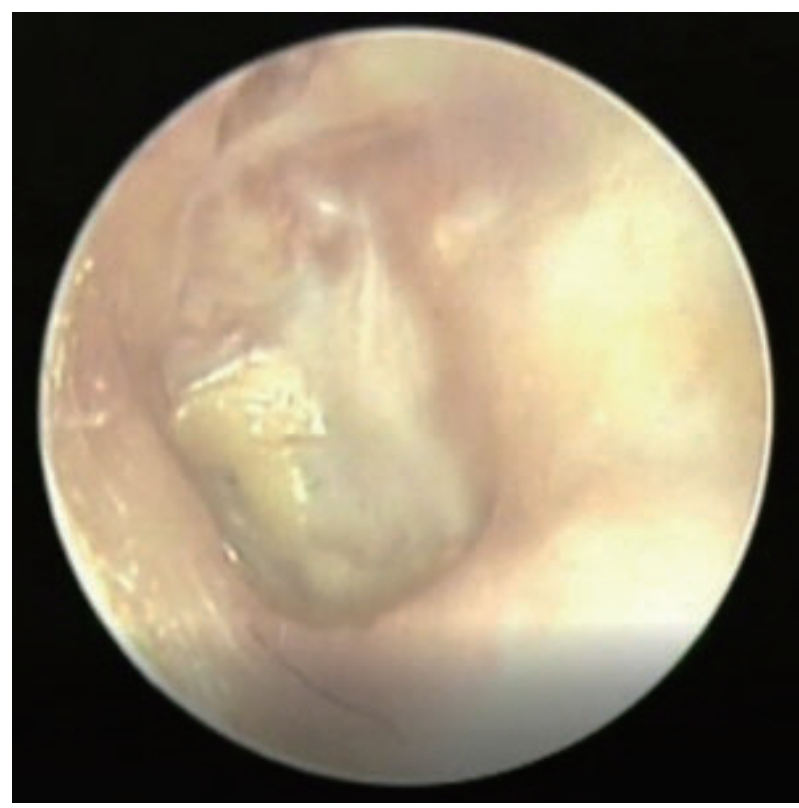

Fig. 6. Endoscopic finding after postoperative 1 year.

부드럽게 만들기 위해 유양동을 골분으로 채운다. 골분으로 채워지지 않은 나머지 부분은 extended $\mathrm{IBF}$ 를 이용하여 채 운다(Fig. 4). 말려두었던 측두근막을 이용하여 고실성형술을 시행해주고 외이도후방의 피부피판을 앞쪽으로는 측두근막, 뒤쪽으로는 extemded IBF 위로 원위치 시켜 준 뒤 외이도에 gelfoam을 패킹한다. 이후 이개 후방의 피하층 및 피부 봉합 후 수술을 마친다(Fig. 5). 다음은 술식을 요약한 영상이다 (Supplementary Video 1).

\section{수술 후 관리(postoperative management)}

수술 2주 후, 현미경을 이용하여 술후 상처치유가 잘 되는 지 확인한다. 이후 1 개월, 3 개월, 6 개월 간격으로 외이도와 고 막의 상태를 추적 관찰한다. 다음은 본 술식으로 수술한 환 자의 술후 1 년째 외이도 및 고막 사진이다(Fig. 6).

\section{결 과}

본 술식은 병변을 좀더 철저하게 제거할 수 있는 개방동 유 양돌기절제술의 장점을 이용하면서도, 외이도성형술을 시행 하지 않는 대신 자가조직을 이용하여 충분한 유양동 폐색을 시행하여 공동문제를 보완하는 술식이다. 유양동 상부의 측 두부위에서 채취한 건강한 피질골을 이용한 골분을 사용하 기 때문에 감염의 위험이 낮고, extended $\mathrm{IBF}$ 를 이용하여 유 양동의 남은 부분을 폐색하기 때문에 추가로 이식재료를 사 용하는 기존의 술식보다 비용적으로 효율적이다. 또한 안면 신경능에서 외이도 입구까지 부드럽게 이어지기 때문에 각질
이동 및 환기가 잘되어 건조한 수술창을 유지할 수 있고 관 찰도 용이하다. 이에 저자들은 유양동의 크기나 경화정도 등 을 고려하여 적응증에 해당되는 환자에 대해서 자가조직을 이용한 유양동 폐색을 시행하는 변형 개방동 유양돌기절제 술을 시행해 볼 것을 제안한다.

\section{Supplementary Video Legend}

Video 1. Modified canal wall down mastoidectomy and mastoid obliteration in the left ear.

\section{Supplementary Materials}

The Data Supplement is available with this article at https://doi. org/10.3342/kjorl-hns.2021.00850.

\section{Acknowledgments}

This study was supported by the Soonchunhyang University Research Fund.

\section{Author Contribution}

Conceptualization: Jong Dae Lee. Data curation: You Young An. Formal analysis: You Young An. Funding acquisition: Jong Dae Lee. Investigation: You Young An, Jong Dae Lee. Methodology: You Young An, Jong Dae Lee. Project administration: You Young An, Jong Dae Lee. Resources: Jong Dae Lee. Software: You Young An, Jong Dae Lee. Supervision: Jong Dae Lee. Validation: You Young An, Jong Dae Lee. Visualization: You Young An, Jong Dae Lee. Writing — original draft: You Young An. Writing — review \& editing: Jong Dae Lee.

\section{ORCIDs}

Jong Dae Lee https://orcid.org/0000-0003-2866-9841

You Young An https://orcid.org/0000-0001-6695-7655

\section{REFERENCES}

1) Brown JS. A ten year statistical follow-up of 1142 consecutive cases of cholesteatoma: The closed vs. the open technique. Laryngoscope 1982;92(4):390-6.

2) Charachon R, Gratacap B, Tixier C. Closed versus obliteration technique in cholesteatoma surgery. Am J Otol 1988;9(4):286-92.

3) Karmarkar S, Bhatia S, Saleh E, DeDonato G, Taibah A, Russo A, et al. Cholesteatoma surgery: The individualized technique. Ann Otol Rhinol Laryngol 1995;104(8):591-5.

4) Sadé J, Weinberg J, Berco E, Brown M, Halevy A. The marsupialized (radical) mastoid. J Laryngol Otol 1982;96(10):869-75.

5) Smyth GD. Canal wall for cholesteatoma: Up or down? Long-term results. Am J Otol 1985;6(1):1-2.

6) Palmgren O. Long-term results of open cavity and tympanomastoid surgery of the chronic ear. Acta Otolaryngol 1979;88(5-6):343-9.

7) Palva T. Operative technique in mastoid obliteration. Acta Otolaryngol 1973;75(4):289-90.

8) Gantz BJ, Wilkinson EP, Hansen MR. Canal wall reconstruction tympanomastoidectomy with mastoid obliteration. Laryngoscope 2005;115(10):1734-40.

9) Lee WS, Choi JY, Song MH, Son EJ, Jung SH, Kim SH. Mastoid and epitympanic obliteration in canal wall up mastoidectomy for prevention of retraction pocket. Otol Neurotol 2005;26(6):1107-11.

10) Black B. Mastoidectomy elimination: Obliterate, reconstruct, or ablate? Am J Otol 1998;19(5):551-7.

11) Dornhoffer JL. Surgical modification of the difficult mastoid cavity. 
Otolaryngol Head Neck Surg 1999;120(3):361-7.

12) Roche P, Coolahan I, Glynn F, Mc Conn WR. Autologous bone pate in middle ear and mastoid reconstruction. Rev Laryngol Otol Rhinol (Bord) 2011;132(4-5):193-6.

13) Grote JJ. Results of cavity reconstruction with hydroxyapatite implants after 15 years. Am J Otol 1998;19(5):565-8.

14) Kim BG, Kim HJ, Lee SJ, Lee E, Lee SA, Lee JD. Outcomes of modified canal wall down mastoidectomy and mastoid obliteration using autologous materials. Clin Exp Otorhinolaryngol 2019;12(4): $360-6$. 